REVISTA EVIDENCIAÇÃO CONTÁBIL \& FINANÇAS

RECFin

João Pessoa, v. 8, n. 3, p. 5-22, Set./Dez. 2020. ISSN 2318-1001

DOI: 10.22478/ufpb.2318-1001.2020v8n3.51368

Disponível em: http://periodicos.ufpb.br/ojs2/index.php/recfin

\title{
REORGANIZAÇÕES SOCIETÁRIAS E AGRESSIVIDADE TRIBUTÁRIA ${ }^{1}$
}

\section{CORPORATE RESTRUCTURINGS AND TAX AGGRESSIVEN}

\author{
Fábio Moraes da Costa \\ Doutor em Ciências Contábeis (USP) \\ FUCAPE Business School \\ fabio@fucape.br
}

Radjalma Lucena Amorim Júnior

Mestre em Ciências Contábeis (FUCAPE RJ)

radjalma@pretorian.net.br

\section{RESUMO}

Objetivo: Verificar se as empresas que realizaram reorganizações societárias apresentam maior nível de agressividade fiscal, tanto em relação às empresas incorporadas quanto em relação aos efeitos da incorporação nas empresas incorporadoras.

Fundamento: O planejamento tributário é uma forma estratégica de aumento de competitividade, de lucratividade e, muitas vezes, de viabilidade do negócio, sendo, por última consequência, uma forma de se obter recursos internamente. Desse modo, a redução de carga tributária oriunda desses instrumentos pode ser um propulsor potencial para a realização do negócio.

Método: Realizou-se a investigação por meio de análise das companhias listadas na Brasil, Bolsa, Balcão (B3) que tiveram seu registro cancelado por incorporação e de suas respectivas incorporadoras. Após a análise para identificação do modelo adequado, rodaram-se os dados em regressão em painel com duplo efeito fixo (firma e ano). Foram coletadas informações para o período entre 2005 e 2017, perfazendo o total de 5.251 observações para a maior amostra estudada. Para a mensuração da agressividade fiscal, utilizou-se a effective tax rate (ETR) em três dimensões: total, corrente e de longo prazo. Para empresas incorporadas, avaliou-se se o nível de agressividade no ano anterior ao da incorporação é diferente. Já para empresas incorporadoras, por meio de um design diff-in-diff, avaliou-se se há efeito sobre o nível de agressividade fiscal após a reorganização societária.

Resultados: Em relação às incorporadoras, de maneira geral, os resultados indicam que não há efeito na taxa efetiva de tributos, quando comparadas ao grupo de controle. Já em relação às empresas incorporadas, foi possível identificar que a taxa efetiva de tributos corrente é menor no ano anterior ao do evento de reorganização societária.

Contribuições: Os resultados sobre a agressividade fiscal para incorporadoras podem contribuir para a adequada compreensão de como planejamentos fiscais agressivos estão relacionados às operações de reorganização societária. Estudos futuros podem buscar comprovação se o perfil a-

\footnotetext{
${ }^{1}$ Artigo recebido em: 24/03/2020. Revisado por pares em: 25/05/2020. Reformulado em: 19/06/2020. Recomendado para publicação: 06/08/2020 por Vagner Antônio Marques (Editor Adjunto). Publicado em: 07/09/2020. Organização responsável pelo periódico: UFPB
} 
gressivo de uma empresa alvo de reorganização pode ser um dos motivos para o negócio acontecer.

Palavras-chave: Agressividade tributária. Planejamento tributário. Incorporações.

\section{ABSTRACT}

Objective: Verify if companies that engage in business combinations present higher levels of tax aggressiveness, either for the acquirer or the acquiree. Specifically, the study focus on companies that decide to incorporate newly acquired subsidiaries.

Background: Tax planning is a strategy in order to make the business viable and enhance returns or the competitiveness of a firm. Thus, reducing the tax burden could be an objective in order for firms to engage in business combinations.

Method: The investigation was based on Brazilian companies listed at 'Brasil, Bolsa, Balcão (B3) that had their registry cancelled by being incorporated by another company. Results were based on panel data regressions with fixed effects (firm and year). We colected data from Economatica from 2005 to 2017. The final sample comprises 5,251 observations. We meausre tax aggressiveness via three dimensions of the effective tax rate (ETR): total, current and lon-term. We evaluate if the level of aggressiveness for the target company is higher in the year before the restructuring takes place. We also evaluate, using a diff-in-diff design, if there is any change in the level of tax aggressiveness for the acquiring company.

Results: In relation to the acquirer, empirical evidence indicate that there is no effect on their effective tax rates when compared to a control group. On the other hand, results indicate that the effective tax rate for the acquirees are lower in the year preceding the business combination.

Contribution: Empirical evidence indicate that the target company may engage in practices of aggressive tax planning in order to become more attractive. On the other hand, despite their level of tax aggressiveness, there is no significant effect on its level for the acquirer company after the business combination. Therefore, results contribute to a better understanding about the dynamics about the level of tax aggressiveness in business combinations.

Keywords: Tax aggressiveness. Tax planning. Corporate restructurings.

\section{INTRODUÇÃO}

O cenário econômico mundial tem progressivamente forçado as empresas a serem mais competitivas, sobretudo pelas mudanças ocorridas nas últimas décadas nos âmbitos político, econômico, comercial e industrial (Jordão \& Oliveira, 2016). Essa concorrência gera uma demanda por práticas de gestão que atuem na melhoria contínua de processos, buscando eficiência operacional, qualidade e minimização de custos de toda ordem, a fim de promover o crescimento e o desenvolvimento.

De acordo com DePamphilis (2017), diversos são os motivos que são capazes de influir uma sociedade empresária a fazer uma reorganização societária, como diminuição de custos fixos e aumento de market share. Assim sendo, a reorganização societária vem obtendo ênfase entre os planos de concorrência econômica pelos motivos citados acima, com o propósito de manter a disputa e incentivar a companhia a desenvolver técnicas e parcerias de natureza tecnológica, operacional, comercial e financeira para conquistar novos mercados, implementar novas técnicas de negócios, centralizando atividades ou separando-as, aprimorando recursos para oferecer produtos e serviços mais competitivos aos consumidores.

De acordo com Reale (1988, p. A-3), a natureza capitalista do sistema econômico brasileiro, consagrada por uma economia de mercado, em que se busca, por meio da livre iniciativa, assegu- 
rar a todos a prática de qualquer atividade econômica, garante "não apenas a livre escolha das profissões e das atividades econômicas, mas também a autônoma eleição dos processos ou meios julgados mais adequados à consecução dos fins previstos".

Com efeito, o cenário brasileiro é caracterizado por um ambiente legal favorável à liberdade de iniciativa dos agentes econômicos, de modo a buscar seu dever de diligência, conforme determina o art. 153 da Lei das Sociedades por Ações, e a finalidade de suas atribuições, conforme o art. 154, caput e $\S 2^{\circ}$ do mesmo diploma legal (Lei n. 6.404, 1976). Ou seja, aos gestores das empresas sujeitas ao ordenamento jurídico brasileiro, cabe administrar as empresas utilizando as melhores técnicas de gestão comercial, operacional, administrativa e financeira, com honestidade, competência e experiência profissional, além do dever de zelo pela legalidade de seus atos em busca de lucro, que, obviamente, garante sua função social e, consequentemente, o bem público.

Segundo Mackenzie (2017), os estudos que apresentam a questão das "fusões e aquisições" se concentram principalmente em transações internacionais; de fato, as transações nacionais são analisadas com menos frequência, ressalta. A autora ainda complementa que, predominantemente, estudos avaliam a atividade de aquisição em economias desenvolvidas, enquanto relatórios sobre o mesmo assunto em economias em desenvolvimento são raros.

Grande parte dos estudos internacionais sugere que existe diminuição da carga tributária das empresas que praticaram eventos de reorganização societária, sobretudo empresas americanas e europeias. É importante verificar se no Brasil esse fenômeno também ocorre, pois este país tem estruturas normativas e mercadológicas diferentes, as operações são relevantes e recorrentes, além do peso da tributação na composição dos custos das empresas brasileiras serem bastante elevados.

No Brasil existem poucos estudos que relacionam agressividade tributária à reorganização societária. Pesquisas até então vêm abordando o tema sob a ótica da eficiência operacional e de gestão, avaliando a quantidade e o valor das transações. Existem, também, pesquisas que tratam da legalidade ou licitude das reorganizações societárias como forma de planejamento tributário (Santos, 2014), ou até sobre o posicionamento dos tribunais administrativos em relação à permissibilidade ou não das benesses tributárias que podem resultar dos eventos (Martinez \& Coelho, 2016).

Esta investigação tomou por base o trabalho de Belz, Robinson, Ruf, \& Steffens (2013), que investigaram mudanças na redução tributária de empresas alvo de fusões e aquisições em uma amostra de fusões e aquisições europeias que ocorreram entre 1996 e 2009. Os autores apresentam resultados que demonstram que, após a realização do negócio, a effective tax rate (ETR) das empresas alvo diminuem.

A agressividade fiscal foi a variável dependente utilizada para medir o grau de agressividade fiscal da amostra, e foi representada pela ETR, que é uma medida utilizada universalmente para a agressividade tributária das empresas (Shackelford \& Shevlin, 2001; Plesko, 2003; Halon \& Heitzman, 2010; Dunbar, Higgins, Phillips, \& Plesko., 2010; Chen, Chen, Cheng, \& Shevlin, 2010; Belz et al., 2013; Blouin, 2014). Como variáveis de controle, foram consideradas as características de tamanho, rentabilidade sobre o ativo e alavancagem. Os dados foram coletados da Economática para o período entre 2005 a 2017, perfazendo 5.251 observações para a maior amostra do estudo.

Os resultados encontrados nesta pesquisa indicam que as empresas, antes de serem incorporadas, têm um nível de agressividade fiscal maior que as demais, porém não demonstram que a agressividade fiscal das incorporadoras pode ser alterada após a concretização do negócio.

Reconhecendo e explorando a lacuna de investigação acima mencionada, a contribuição à pesquisa acadêmica se dá, pois, de forma precursora, contempla um ciclo operacional importante (antes e depois da realização dos negócios) dentro do universo temporal estudado, e de maneira objetiva analisa a agressividade fiscal em que pese as métricas e seus modelos estatísticos utilizados, verificando o nível de agressividade das empresas incorporadas um ano antes da realização 
do negócio e se após a incorporação houve aumento de agressividade fiscal. Os resultados, além de contribuírem com a comunidade acadêmica, servindo de base para outros estudos, também podem ajudar a comunidade empresária a entender o comportamento tributário das empresas antes e depois do acontecimento dos negócios, sendo esse entendimento um elemento importante para a tomada de decisões estratégicas, além de auxiliar o fisco, que, na realidade brasileira, demonstra sua preocupação à licitude dos efeitos tributários desses eventos.

\section{FUNDAMENTAÇÃO TEÓRICA}

A relação entre reorganizações societárias e agressividade fiscal pode resultar em um aumento de despesas operacionais dedutíveis de tributos, diminuindo a base de cálculo dos impostos, a exemplo do ágio, juros, despesas legalmente incentivadas (depreciação acelerada), entre outros custos. Também é possível aproveitar o prejuízo fiscal pela incorporadora por meio do lucro tributável que pode ser gerado, fruto da sinergia dessas entidades.

Mediante a consolidação de corporações empresariais, é possível tributar lucros em regiões incentivadas de maneira mais eficiente no caso brasileiro, mensurando e registrando obrigações de performance distintas (receitas) em relação a quando, quanto e onde se deve determinar o preço das transações. Por meio da cisão de corporações, é possível separar seguimentos ou operações com margens de lucro tributáveis diferentes e aproveitar respectivos créditos tributários correntes, adequando ao melhor modelo de tributação permitido pela legislação vigente.

Belz et al. (2013) afirmam que diminuir o peso tributário de uma empresa alvo é um caminho importante para que uma empresa adquirente possa trilhar e gerar vantagens em ser proprietária. Sempre que há uma incorporação, espera-se que o incorporador obtenha vantagens, fruto do negócio. Essas vantagens esperadas podem ser de várias ordens, dentre elas, a vantagem tributária não poderia ser ignorada em um país que tem uma das mais altas cargas tributárias do mundo.

No cenário brasileiro, observa-se um volume significativo de reorganizações societárias ocorrida nos últimos anos, e esses eventos estão sob o radar do fisco, gerando discussões (fisco $x$ contribuinte) nos âmbitos judiciais e administrativos sobre a licitude ou não de possíveis ganhos tributários obtidos após os instrumentos de reorganização societária. Com efeito, caso o alvo de uma incorporação tenha uma agressividade fiscal acentuada em relação às demais empresas antes da concretização do negócio, ele se tornaria "um alvo" interessante sob o aspecto tributário, porém só se saberia se de fato as vantagens aconteceram caso as incorporadoras aumentassem seu nível de agressividade em relação à média das empresas após o negócio.

Desse modo, as hipóteses foram desenvolvidas no sentido de verificar se as empresas que se envolveram em eventos de reorganização societária têm o nível de agressividade fiscal alto antes dos eventos relativos às empresas alvo (incorporadas) e após os eventos relativos às empresas incorporadoras, demonstrando se a economia tributária pode "ou não" ser um fator relevante para a concretização desses negócios.

\subsection{Reorganizações Societárias}

As ações de reorganização societária existem há muito tempo no mundo corporativo. Desde que a divisão entre proprietários e empresas e as sociedades empresariais foram criadas, existem ações de aquisições, divisões e vendas de empresas.

Bowman (1993) explica que a reorganização societária tem despertado a atenção de todos que estudam e militam nas áreas de estratégia e finanças corporativas e gestão. O ganho competitivo que pode vir em razão dessa mudança estrutural tem sido alvo de pesquisadores de estratégia corporativa e de teoria organizacional.

Assim sendo, apresentam-se os principais métodos de reorganizações societárias: aquisição/venda, fusão, incorporação, cisão e transformação. 


\subsubsection{Motivos para a reorganização societária}

De acordo com Mackenzie (2017), no que diz respeito às reorganizações societárias, a atividade de transação pode ser significativamente influenciada pelas condições externas de um país, ou seja, seu ambiente legal, econômico, político e social. O Quadro 1, apresentado a seguir, foi construído a partir da publicação de DePamphilis (2017), trazendo uma lista das principais teorias e motivações largamente discutidas na literatura acerca dos motivos para a reorganização societária.

Quadro 1 - Teorias comuns das motivações das reorganizações societárias

\begin{tabular}{|c|c|}
\hline Teoria & Motivação \\
\hline $\begin{array}{l}\text { Sinergia operacional } \\
\text { - Economias de escala } \\
\text { - Economias de escopo } \\
\text { - Recursos téc./hab. complementares }\end{array}$ & $\begin{array}{l}\text { Melhorar a eficiência operacional com economias de escala ou esco- } \\
\text { po. Adquirindo um cliente, fornecedor ou concorrente, com o intui- } \\
\text { to de aprimorar habilidades técnicas ou inovadoras. }\end{array}$ \\
\hline Sinergia Financeira & Menor custo de capital. \\
\hline $\begin{array}{l}\text { Diversificação } \\
\text { - Novos produtos/mercados atuais } \\
\text { - Novos produtos/novos mercados } \\
\text { - Produtos atuais/novos mercados }\end{array}$ & $\begin{array}{l}\text { Posicionar a empresa em produtos ou mercados de maior cresci- } \\
\text { mento. }\end{array}$ \\
\hline $\begin{array}{l}\text { Realinhamento Estratégico } \\
\text { - Mudanças tecnológicas } \\
\text { - Mudanças políticas e regulatórias }\end{array}$ & $\begin{array}{l}\text { Adquirir capacidades para se adaptar mais rapidamente às mudan- } \\
\text { ças de mercado, de forma mais acelerada do que seria se estas modi- } \\
\text { ficações fossem desenvolvidas internamente. }\end{array}$ \\
\hline $\begin{array}{l}\text { Excesso de confiança } \\
\text { (orgulho gerencial) }\end{array}$ & $\begin{array}{l}\text { Compradores acreditam que a sua avaliação do alvo é mais precisa } \\
\text { que a do mercado, levando-os a pagar muito mais em função de ter } \\
\text { superestimado a sinergia. }\end{array}$ \\
\hline $\begin{array}{l}\text { Compra de ativos subavaliados } \\
\text { (Q de Tobin) }\end{array}$ & $\begin{array}{l}\text { Adquirir ativos de forma mais barata quando o capital de socieda- } \\
\text { des existentes é menor do que o custo de comprar ou construir ati- } \\
\text { vos. }\end{array}$ \\
\hline Problemas do principal-agente & $\begin{array}{l}\text { Aumentar o tamanho de uma empresa para aumentar o poder e o } \\
\text { salário do administrador desta. }\end{array}$ \\
\hline Considerações fiscais & $\begin{array}{l}\text { Obter perdas operacionais líquidas não utilizadas, créditos fiscais e } \\
\text { reduções de ativos. Substituir ganhos de capital por receita ordiná- } \\
\text { ria. }\end{array}$ \\
\hline Poder de mercado & $\begin{array}{l}\text { Ações tomadas para impulsionar os preços de venda acima dos } \\
\text { níveis competitivos, afetando ou a oferta ou a demanda. }\end{array}$ \\
\hline Desvalorização & $\begin{array}{l}\text { A supervalorização das ações do adquirente o encoraja para fazer } \\
\text { aquisições ou fusões utilizando estas suas ações. }\end{array}$ \\
\hline
\end{tabular}

Fonte: Adaptado de DePamphilis (2017)

\subsubsection{Aquisição/venda}

As operações de aquisição, segundo Ridolfo Neto (2012), são ações em que uma empresa passa a controlar outra(s). A ação pode ser desenvolvida como venda de ações da empresa ou venda de ativos. Essas operações podem ser uma "união espontânea" entre empresas similares, uma compra amistosa de uma empresa por outra, ou uma aquisição adversa de uma empresa por outra. A compra/venda é a transferência da propriedade ou ações de uma empresa para outra.

Segundo Gaughan (2011), diversas são as razões que podem fazer uma empresa se reestruturar em eventos de reorganização societária. Os motivos mais recorrentes são os de aumento em participação de mercado. Incorporar ou adquirir uma empresa ou uma linha de produção dela em áreas geográficas de mercados estratégicos pode ser o caminho mais célere para a expansão ou fortalecimento da empresa aquisitora ou incorporadora. $\mathrm{O}$ resultado desses eventos pode trazer várias vantagens, sobretudo quando o seguimento que ora foi incorporado ou adquirido é o mes- 
mo ou seria um seguimento que estivesse faltando na operação da empresa aquisitora ou incorporadora, dando completude à operação.

\subsubsection{Fusão}

O conceito legal de fusão está no art. 228 da Lei das Sociedades por Ações: “A fusão é a operação pela qual se unem duas ou mais sociedades para formar sociedade nova, que lhes sucederá em todos os direitos e obrigações" (Lei n. 6.404, 1976, p. 86). O resultado do movimento de fusão são duas empresas que se unem, transformando seu patrimônio para a constituição de uma terceira empresa, que predomina sobre as outras, uma vez que as duas anteriores passam a não mais existir.

Internacionalmente, o termo fusão de empresas tem conotação diferente do indicado na Lei das Sociedades por Ações. Segundo DePamphilis (2017), uma fusão é uma combinação de duas ou mais empresas, muitas vezes comparáveis em tamanho, em que todas, exceto uma, deixam de existir legalmente. Uma fusão estatutária ou direta é aquela em que a empresa adquirente ou sobrevivente assume automaticamente os ativos e passivos do alvo de acordo com os estatutos do Estado em que as empresas combinadas serão incorporadas.

DePamphilis (2017) também pontua o termo internacional que é aproximado com o que no Brasil é considerado uma fusão, que é: statutory consolidation. Uma statutory consolidation envolve duas ou mais empresas para formar uma nova empresa, que, segundo DePamphilis (2017), não é tecnicamente uma fusão. As pessoas jurídicas envolvidas no processo deixam de existir e passam a ter um novo nome. As ações em poder dos acionistas também são trocadas pelas ações da nova empresa.

\subsubsection{Incorporação}

O art. 227 da Lei das Sociedades por Ações assim conceitua incorporação: “A incorporação é a operação pela qual uma ou mais sociedades são absorvidas por outra, que lhes sucede em todos os direitos e obrigações" (Lei n. 6.404, 1976, p. 86). De acordo com o texto legal, na incorporação a empresa ora incorporada não existe mais no ordenamento jurídico e seu patrimônio é incorporado ao patrimônio da empresa incorporadora, que continua com a sua personalidade jurídica, fazendo a assunção total dos dois patrimônios.

Martins, Gelbcke, Santos, \& Iudícibus (2013) explicam que, na incorporação, quando uma controladora incorpora sua única controlada, suas demonstrações contábeis após o evento ficarão praticamente iguais às demonstrações consolidadas antes da concretização da reorganização. A única mudança será no patrimônio líquido, em razão da participação dos não controladores, que será incorporada ao capital social. Isso porque não há consolidação proporcional nas normas contábeis brasileiras e internacionais.

\subsubsection{Cisão}

A operação de cisão entre empresas, segundo definem Terres Junior, Borba e Souza (2011), é uma operação entre duas ou mais empresas em que há a cessão de uma parte ou do total do patrimônio líquido para uma ou mais empresas. Quando o patrimônio líquido é cedido totalmente, a empresa cindida deixa de existir.

A Lei das Sociedades por Ações também traz a definição legal do termo cisão no art. 229: 
A cisão é a operação pela qual a companhia transfere parcelas do seu patrimônio para uma ou mais sociedades, constituídas para esse fim ou já existentes, extinguindo-se a companhia cindida, se houver versão de todo o seu patrimônio, ou dividindo-se o seu capital, se parcial a versão (Lei n. 6.404, 1976, p. 86).

Existem diferentes modalidades de cisão de empresas, sendo total ou parcial. Terres Junior et al. (2011) explicam que, na cisão total, o patrimônio líquido é cedido totalmente, extinguindo-se a empresa cindida e dando origem a novas empresas, sendo-lhes transferidos todos os seus direitos e obrigações. Na cisão parcial, apenas uma parte do patrimônio líquido é transferido a outras empresas, e a empresa cindida parcialmente continua a existir.

\subsubsection{Transformação}

A transformação é conceituada no art. 220 da Lei das Sociedades por Ações da seguinte forma: "A transformação é a operação pela qual a sociedade passa, independentemente de dissolução e liquidação, de um tipo para outro." (Lei n. 6.404, 1976, p. 83). Um exemplo de transformação é a mudança de uma sociedade anônima que se transforma em uma sociedade limitada.

Segundo Martins et al. (2013), a transformação requer o consentimento unânime dos sócios ou acionistas, salvo se prevista no estatuto ou no contrato social, caso em que o sócio dissidente terá o direito de retirar-se da sociedade. Quando a Lei das Sociedades por Ações não for suficiente para dar um aspecto legal à operação de transformação, pode-se utilizar dos textos dos arts. 1.113 ao 1.115 do Código Civil, que assim instrui:

Art. 1.113. $\mathrm{O}$ ato de transformação independe de dissolução ou liquidação da sociedade, e obedecerá aos preceitos reguladores da constituição e inscrição próprios do tipo em que vai converter-se.

Art. 1.114. A transformação depende do consentimento de todos os sócios, salvo se prevista no ato constitutivo, caso em que o dissidente poderá retirar-se da sociedade, aplicando-se, no silêncio do estatuto ou do contrato social, o disposto no art. 1.031.

Art. 1.115. A transformação não modificará nem prejudicará, em qualquer caso, os direitos dos credores.

Parágrafo único. A falência da sociedade transformada somente produzirá efeitos em relação aos sócios que, no tipo anterior, a eles estariam sujeitos, se o pedirem os titulares de créditos anteriores à transformação, e somente a estes beneficiará (Lei n. 10.406, 2002).

\subsection{Agressividade Tributária}

A despeito desse tema, não há uma só descrição no que diz respeito ao planejamento tributário. Assim sendo, trata-se de movimentos e estruturações jurídicas, contábeis e físicas (locacionais) que busquem a diminuição, retardo, desobrigação ou não aplicação de obrigações tributárias. Pode também ser definido como todas as transações que reduzem os impostos, sejam estas legais ou ilegais (Hanlon \& Heitzman, 2010).

De acordo com Blouin (2014), o planejamento tributário, em geral, é interpretado como benéfico para a empresa e seus acionistas, contanto que a elaboração dos custos tributários resulte maiores movimentos de caixa e lucro líquido para a empresa e, consequentemente, para seus acionistas. Porém, é de fundamental importância a lição de Scholes e Wolfson (1992), que ensinam que 
um planejamento tributário somente pode ser eficaz se a empresa considerar custos tributários e não tributários, ou seja, todas as partes, todos os tributos e todos os custos.

\subsubsection{Agressividade tributária no contexto brasileiro}

Os contribuintes, com o intuito de diminuir a carga tributária brasileira, cada dia mais investem em planejamento tributário, buscando escapar da ação dos fatos geradores de tributos e da origem de obrigações tributárias. A fim de evitar a prática de tais atos, o parágrafo único do art. 116 do Código Tributário Nacional, incluído pela Lei Complementar n⿳0 104/2001, principiou na organização jurídica nacional a norma geral antielisão, que diz:

A autoridade administrativa poderá desconsiderar atos ou negócios jurídicos praticados com a finalidade de dissimular a ocorrência do fato gerador do tributo ou a natureza dos elementos constitutivos da obrigação tributária, observados os procedimentos a serem estabelecidos em lei ordinária (Lei n. 5.172, 1966; Lei Complementar n. 104, 2001).

Desse modo, a Fazenda está habilitada a escapar da diretriz tributária estabelecida na presunção de incidência do tributo, sendo capaz de alcançar circunstâncias que não estavam nela previstas. Segundo Flávio Neto (2011), esse método mantém-se sem êxito, principalmente porque o seu enunciado requer, expressamente, que seja expresso em lei ordinária, que regulamentará um processo específico para a sua aplicação.

Schoueri (2015) afirma que, dentro da legislação brasileira, ainda não se determinou o significado de planejamento tributário, planejamento tributário abusivo ou planejamento tributário agressivo, deixando, assim, todos esses jargões expostos à ambiguidade jurídica. O mesmo aconteceu na esfera das normas administrativas. Sabendo da ambiguidade jurídica acerca do tema no Brasil, fatalmente erguem-se incertezas do que é apropriado fazer para diminuir, retardar ou remover a incidência de tributos (tax avoidance). A dificuldade é agravada muito em função das figuras jurídicas tais como "simulação" ou "fraude na lei", as quais são comumente utilizadas de forma inadequada ou, às vezes, nem chegam a ser aplicadas (Martinez \& Coelho, 2016).

Existe um movimento político que impacta as ações do fisco no sentido de combater as ações que são agressivas tributariamente, isso pela necessidade de arrecadação tributária do governo. Ao viés de a norma antielisiva não estar totalmente regulamentada, os entes de fiscalização tributária têm conseguido ferramentas de enfrentamento à sonegação e ao planejamento tributário agressivo (Martinez, 2017).

\subsubsection{Estratégia e planejamento tributário em reorganização societária}

A reorganização societária é uma das estratégias disponíveis para o planejamento tributário, sendo este um assunto com certa difusão em publicações no meio acadêmico. Jensen e Ruback (1983) sugerem que operações de reorganização societária podem ser motivadas por razões tributárias, pois as empresas seriam atraídas pela oportunidade de utilizar totalmente os benefícios fiscais, aumentar a alavancagem e explorar outras vantagens fiscais.

O estudo de Hayn (1989) examinou uma amostra de 640 aquisições durante 1970 e 1985 e descobriu que os retornos anormais do período de anúncios estão associados positivamente com os atributos fiscais da empresa alvo, tais como: prejuízos operacionais líquidos, créditos fiscais não utilizados e maior depreciação devido ao aumento na base dos ativos adquiridos. Ela concluiu que as considerações tributárias poderiam motivar aquisições.

Kaplan (1989) estudou aquisições de 76 empresas no período entre 1980 e 1986, mostrando que essas reorganizações trouxeram uma economia fiscal de até 126\%. Devos, Kadapakkam, \& 
Krishnamurthy (2009), ao analisarem 264 grandes operações de fusões societárias, também verificaram economia fiscal nas operações.

Blouin, Collins, \& Shackelford (2005) examinaram as mudanças em rendimentos tributáveis de empresas estadunidenses após serem adquiridas por firmas estrangeiras, e não encontraram evidências de que o lucro tributável diminui mais após a aquisição por firmas estrangeiras do que por firmas nacionais.

Belz et al. (2013), ao indagarem se a elisão fiscal era fato que induzia empresas europeias a realizarem operações de fusões e aquisições, concluíram que houve uma maior elisão tributária dentro dos alvos pós-aquisição, aumentando, assim, o fluxo de caixa disponível para os compradores, permitindo que os compradores superem os proprietários iniciais. Segundo os autores, o tax avoidance seria um dos grandes motivos para as operações de reorganização societárias.

No Brasil, segundo Martinez (2017), a literatura acadêmica nacional já tem algumas publicações, mas ainda tem pouco a oferecer acerca da agressividade fiscal em reorganização societária, pois o país tem uma realidade diferente de países europeus ou norte-americanos. Na esfera jurídica, Martinez (2017) explica que o planejamento tributário abusivo não tem o mesmo significado que a evasão fiscal, tendo em vista que o primeiro é legal e o segundo ilegal. Entretanto, o planejamento tributário agressivo fica sujeito à má interpretação e a questionamentos em tribunais administrativos.

\subsubsection{Medidas de agressividade tributária}

No intuito de medir a agressividade tributária, algumas medidas e métricas foram desenvolvidas ao longo do tempo (Omer, Molloy, \& Ziebart, 1991; Callihan, 1994; Shackelford \& Shevlin, 2001; Plesko, 2003; Halon \& Heitzman, 2010; Dunbar, Higgins, Phillips, \& Plesko, 2010; Chen et al., 2010; Belz et al., 2013; Blouin, 2014).

Entre todas as métricas, destaca-se a ETR, que logo se tornou uma medida utilizada de forma universal na mensuração da agressividade fiscal das empresas (Shackelford \& Shevlin, 2001; Plesko, 2003; Halon \& Heitzman, 2010; Dunbar et al., 2010; Chen et al., 2010; Belz et al., 2013; Blouin, 2014). Destaca-se, também, além da ETR, a book-tax difference (BTD), que foi mostrada no estudo de Hanlon e Heitzman (2010), os quais revisaram pesquisas fiscais anteriores e chegaram à conclusão que tanto a ETR quanto a BTD são importantes como métricas da agressividade fiscal.

Segundo Dunbar et al. (2010), a ETR das empresas é uma medida de obrigação tributária dividida pela renda, e tem sido usada na literatura como uma medida do planejamento tributário ativo. Dunbar et al. (2010) também fizeram uma revisão de diversas métricas de agressividade fiscal, chegando à conclusão que na literatura existem quatro variantes da ETR, duas baseadas em BTD e as demais mensuram comportamentos anormais em planejamento tributário.

\section{METODOLOGIA}

\subsection{Parâmetros de Seleção da Amostra}

A amostra foi composta por empresas de capital aberto listadas na Brasil, Bolsa, Balcão (B3), entre os anos de 2005 e 2017, com cada observação em escala anual.

Na Tabela 1 é apresentado o número de observações existentes por variável estudada, para cada ano. Elas foram divididas em existentes e faltantes. A explicação detalhada sobre cada variável será dada na seção 3.3. As diferenças existentes entre as observações a cada ano referem-se ao cancelamento ou à inclusão de empresas na listagem da B3 e à disponibilidade de dados no sistema Economatica ${ }^{\circledR}$. Em cada ano, há um total de 708 observações para as variáveis Grau de Alavancagem (LEV) e Retorno sobre o Ativo (ROA), e há dados faltantes para as demais. No total, há 9.204 observações para LEV e ROA. 
Tabela 1 - Número de observações das variáveis

\begin{tabular}{lrrr}
\hline \multirow{2}{*}{ Variável } & \multicolumn{3}{c}{ Observações para cada variável } \\
\cline { 2 - 4 } & Total & Faltantes & Existentes \\
\hline ETR_Total & 9.204 & 3.956 & 5.248 \\
ETR_Corrente & 9.204 & 3.956 & 5.248 \\
ETR_Longo_Prazo & 9.204 & 3.613 & 5.591 \\
SIZE & 9.204 & 3.908 & 5.296 \\
LEV & 9.204 & 0 & 9.204 \\
ROA & 9.204 & 0 & 9.204 \\
\hline
\end{tabular}

ETR_Total, ETR_Corrente, ETR_Longo_Prazo: medidas de agressividade tributária; SIZE: logaritmo natural do ativo total de firma; ROA: lucro operacional dividido pelo ativo total; LEV: dívida de longo prazo dividido por ativo total. Fonte: Dados da pesquisa.

\subsection{Técnica de Coleta de Dados}

Os dados foram coletados por meio do banco de dados Economatica ${ }^{\circledR}$. Nele, estavam contidas as demonstrações contábeis de companhias abertas, com base na análise da lista das empresas que cancelaram o registro na B3 por motivo de incorporação, selecionando-se as empresas incorporadas e incorporadoras.

\subsection{Modelos de Regressão}

Os modelos apresentados têm por objetivo verificar se existem relações entre a agressividade tributária e aspectos relacionados à incorporação de empresas. $\mathrm{O}$ foco da pesquisa, portanto, está centrado tanto no nível de agressividade da empresa incorporada quanto em um potencial efeito sobre a incorporadora.

Para avaliar se o nível de agressividade fiscal no ano que antecede a incorporação é diferente, foram identificadas empresas incorporadas por meio de uma variável indicadora (Dummy-I), que assume o valor de 1 para o ano da incorporação e 0 para os demais casos. Para tanto, foi testado o seguinte modelo:

$$
\text { Agressividade Fiscalit }=\beta_{0}+\beta_{1} \text { Dummy-Iit+1 }+\beta_{2} S I Z E_{i t}+\beta_{3} R O A_{i t}+\beta_{4} L E V_{i t}+\varepsilon_{i t}
$$

No caso das incorporadoras, e com o objetivo de avaliar se a reorganização societária trouxe efeitos em seu nível de agressividade fiscal, foi empregada uma variável indicadora (Dummy$N$ ), que assume o valor de 1 para incorporadoras nos anos após a incorporação e 0 para os demais casos.

$$
\text { Agressividade Fiscalit }=\gamma_{0}+\gamma_{1} \text { Dummy }-N_{i t}+\gamma_{2} S I Z E_{i t}+\gamma_{3} R O A_{i t}+\gamma_{4} L E V_{i t}+\delta_{i t}
$$

Em que:

Agressividade Fiscalit: variável dependente que mede o grau de agressividade fiscal de uma empresa $i$ em um ano $t$. Há três variáveis que são candidatas a representá-la: ETR_Total, ETR_Corrente e ETR_Longo_Prazo:

a)ETR_Totalit: calculada como a divisão entre a despesa total com impostos no ano $t$ e o lucro antes do imposto no mesmo período para a empresa $i$;

b) ETR_Correnteit: calculada como a divisão entre despesas com impostos correntes no ano $t$ e o lucro antes do imposto no mesmo período para a empresa $i$;

c) ETR_Longo_Prazoit: medida pelo somatório das despesas de impostos dividido pelo somatório do LAIR. Captura o efeito da tributação em longo prazo (de $3 \mathrm{em} 3$ anos, $t$ corrente e 2 anos anteriores); 
Dummy-Iit+1: variável dummy com valor igual 1 para empresa $i$ que foi cancelada por processo de incorporação no ano $t+1$, e 0 para os demais casos;

Dummy- $N_{i t}$ : variável dummy com valor igual 1 para empresa $i$ incorporadora e somente para os anos após a incorporação, e 0 para os demais casos;

Controlesit: variáveis de controle utilizadas para expurgar os efeitos de outras variáveis consideradas relevantes na determinação da agressividade fiscal:

a) SIZE it: tamanho da companhia mensurado como o logaritmo natural do ativo total da empresa $i$ no ano $t$;

b) ROA it: retorno sobre ativo calculado como lucro operacional da empresa $i$ no instante $t$ dividido pelo ativo total no período $t-1$;

c) $L E V_{i t:}$ alavancagem da empresa $i$ no tempo $t$, sendo medida como a razão entre a dívida de longo prazo e o ativo do ano anterior;

$\varepsilon_{i t}, \delta_{i t}$ : termos de erro relativos à empresa $i$, no instante $t$; e

$\beta_{k}$ e $\gamma_{k}$ : coeficientes a serem estimados.

Em relação às variáveis de controle, Chen et al. (2010) entendem que as empresas mais lucrativas são mais propensas a terem maior ETR, o que justifica a introdução das variáveis de controle retorno sobre ativos (ROA) e grau de alavancagem (LEV). Martinez, Ribeiro, \& Funchal (2015) sugerem que o tamanho (SIZE) das empresas é um determinante de agressividade fiscal.

Os modelos foram estimados por meio das seguintes técnicas: mínimos quadrados agrupados, painel de efeitos fixos, painel de efeitos fixos com dummies temporais e painel de efeitos aleatórios. Além disso, cada modelo foi executado para dois tipos de amostra: o primeiro tipo refere-se considera apenas observações que possuem ETR não negativo, e o segundo se deu para a amostra toda.

De modo a realizar a seleção adequada dos estimadores apresentados, foram realizados os testes de Hausmann e de Breusch-Pagan. Os resultados do teste de Breusch-Pagan apresentam, para os modelos com todas as medições distintas das variáveis dependentes e para diferentes conjuntos de observações, valor-p igual a 0,00. Tal fato indica que o estimador de efeitos aleatórios é preferível ao estimador de mínimos quadrados empilhados, tanto no grupo com ETR $\geq 0$ quanto no conjunto com todos os valores de ETR.

Para que se decida entre os estimadores de efeitos fixos e de efeitos aleatórios, o teste de Hausmann, em todas as mensurações da variável dependente, apresentou valor-p inferior a 1\%, no caso da amostra com ETR $\geq 0$, e valor-p inferior a 5\%, no caso da amostra completa. Isso significa que o primeiro estimador é preferível ao segundo, em todos os casos. Portanto, os testes apontam que o estimador de efeitos fixos é o mais adequado para os dados. Neste sentido, os resultados para cada um dos modelos são baseados em painéis com efeitos fixos.

\section{RESULTADOS E DISCUSSÃO}

Nessa seção são descritos os resultados da pesquisa por meio de estatística descritiva e de regressão.

\subsection{Resultados da Estatística Descritiva}

As estatísticas descritivas estão apresentadas na Tabela 2 para as variáveis contínuas estudadas (média, desvio padrão, mínimo e máximo) e nas Tabelas 3 e 4 para as variáveis dicotômicas (frequência relativa e acumulada). No intuito de se eliminarem as influências devido aos outliers, foi utilizada a técnica de winsorizing dos dados de cada variável para valores abaixo do $3^{\circ}$ percentil e acima do $97^{\circ}$ percentil. 
Tabela 2 - Estatísticas descritivas (winsorized)

\begin{tabular}{lrrrrr}
\hline Variável & Observações & Média & Desvio padrão & Mínimo & Máximo \\
\hline ETR_Total & 5.247 & 0,16 & 0,26 & $-0,55$ & 0,89 \\
ETR_Corrente & 5.247 & 0,15 & 0,25 & $-0,46$ & 0,87 \\
ETR_Longo_Prazo & 5.251 & 0,15 & 0,25 & $-0,56$ & 0,83 \\
SIZE & 5.251 & 13,59 & 2,85 & 4,67 & 17,82 \\
ROA & 5.251 & $-4,34$ & 25,09 & $-92,20$ & 17,68 \\
LEV & 5.251 & 1,21 & 3,18 & $-6,84$ & 8,57 \\
\hline
\end{tabular}

ETR_Total, ETR_Corrente, ETR_Longo_Prazo: medidas de agressividade tributária; SIZE: logaritmo natural do ativo total de firma; ROA: lucro operacional dividido pelo ativo total; LEV: dívida de longo prazo dividido por ativo total. Fonte: Dados da pesquisa.

Dentre as variáveis dependentes (ETR), a média e o desvio padrão são, aproximadamente, 0,16 e 0,26, respectivamente. Dentre as variáveis de controle, SIZE possui média 13,59 e desvio padrão 2,85; ROA possui os valores de -4,34 e 25,09 para a média e o desvio padrão, respectivamente; e, por fim, LEV possui os valores de 1,21 e 3,18, respectivamente.

Tabela 3 - Estatísticas descritivas da variável Dummy-I

\begin{tabular}{lrrr}
\hline Dummy-I & Frequência & Percentual & Acumulado \\
\hline 0 & 5.224 & 99,49 & 99,49 \\
1 & 27 & 0,51 & 100,00 \\
\hline Total & 5.251 & 100,00 & \\
\hline
\end{tabular}

Dummy-I: variável dummy com valor igual 1 para empresa $i$ que foi cancelada por processo de incorporação no ano $t+1, \mathrm{e}$ 0 para os demais casos.

Fonte: Dados da pesquisa.

Tabela 4 - Estatísticas descritivas da variável Dummy-N

\begin{tabular}{lrrr}
\hline Dummy-N & Frequência & Percentual & Acumulado \\
\hline 0 & 4.974 & 94,72 & 94,72 \\
1 & 277 & 5,28 & 100,00 \\
\hline Total & 5.251 & 100,00 & \\
\hline
\end{tabular}

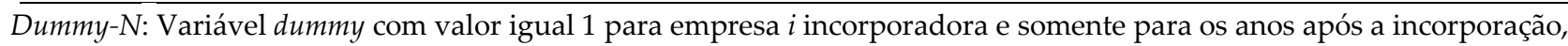
0 para os demais casos.

Fonte: Dados da pesquisa.

Tabela 5 - Matriz de correlação (winsorized)

\begin{tabular}{lllllll}
\hline Variável & ETR_Total & ETR_Corrente & ETR_Longo_Prazo & SIZE & ROA & LEV \\
\hline ETR_Total & 1 & & & & & \\
ETR_Corrente & $0,4208^{* * *}$ & 1 & & & & \\
ETR_Longo_Prazo & $0,4012^{* * *}$ & $0,2461^{* * *}$ & 1 & 1 & \\
SIZE & $0,169^{* * *}$ & $0,1959^{* * *}$ & $0,1835^{* * *}$ & $0,5784^{* * *}$ & 1 \\
ROA & $0,2384^{* * *}$ & $0,2519^{* * *}$ & $0,2330^{* * *}$ & $0,088^{* * *}$ & $0,1065^{* * *}$ & 1 \\
LEV & $0,0251^{*}$ & $0,0567^{* * *}$ & $0,0841^{* * *}$ &
\end{tabular}

ETR_Total, ETR_Corrente, ETR_Longo_Prazo: medidas de agressividade tributária; SIZE: logaritmo natural do ativo total de firma; ROA: lucro operacional dividido pelo ativo total; LEV: dívida de longo prazo dividido por ativo total. *Significante a $10 \% ;{ }^{* *}$ Significante a $5 \% ;{ }^{* * *}$ Significante a $1 \%$.

Fonte: Dados da pesquisa.

Originalmente, a variável dicotômica Dummy-I possui valor igual a 1 em 64 observações. Porém, devido às restrições relacionadas ao uso das demais variáveis no modelo da equação 1 , a amostra final conta com 27 empresas incorporadas, perfazendo 0,51\% da amostra. Já a variável dicotômica Dummy-N possui valor igual a 1 em 277 observações. Houve 39 empresas incorporadoras distintas efetuando incorporações durante o período estudado. 


\subsection{Resultados do Modelo de Regressão}

Nesta seção apresentam-se as regressões efetuadas para o estudo. Foram utilizados os estimadores de mínimos quadrados agrupados, painel de efeitos fixos, painel de efeitos fixos com variáveis dummies temporais e efeitos aleatórios. Em seguida, foram feitos testes para a escolha do melhor estimador. Em todas as situações, as regressões foram rodadas com erros padrão robustos à heterocedasticidade.

Para cada estimador e proxy de agressividade fiscal, foram feitas regressões utilizando a amostra sem corte e com corte no nível da variável ETR, considerando somente as observações com o respectivo ETR $\geq 0$. É conveniente mencionar que, para ambas as hipóteses testadas, o que se almeja é que os coeficientes das variáveis dummies para incorporadoras e incorporadas sejam estatisticamente significativos e negativos, pois, deste modo, haveria alguma evidência no sentido de aumento de agressividade tributária. O sinal negativo implica relação inversa entre mudanças na variável independente a que se refere o coeficiente e na dependente (enquanto uma aumenta, a outra tende a diminuir, na média). É de se notar que, quando o sinal do coeficiente é positivo, um aumento na variável independente corresponde a um aumento na variável dependente, na média.

\subsubsection{Modelo 1}

O Modelo 1 visa avaliar se a média do nível de agressividade fiscal das empresas que foram incorporadas é diferente das demais companhias do mercado. Os resultados com diferentes especificações do Modelo 1 são apresentados na Tabela 6.

Tabela 6 - Resultados da regressão por efeitos fixos acrescidos de dummies temporais (modelo 1)

\begin{tabular}{lllllll}
\hline \multirow{2}{*}{ Variáveis independentes } & \multicolumn{2}{l}{ Variável dependente (ETR $\geq 0)$} & \multicolumn{2}{c}{ Variável dependente (sem corte) } \\
\cline { 2 - 7 } & $\begin{array}{l}\text { ETR_ } \\
\text { Total }\end{array}$ & $\begin{array}{l}\text { ETR_ } \\
\text { Corrente }\end{array}$ & $\begin{array}{l}\text { ETR_ } \\
\text { Longo_Prazo }\end{array}$ & $\begin{array}{l}\text { ETR_ } \\
\text { Total }\end{array}$ & $\begin{array}{l}\text { ETR_ } \\
\text { Corrente }\end{array}$ & $\begin{array}{l}\text { ETR_ } \\
\text { Longo_Prazo }\end{array}$ \\
\hline Estimador selecionado & $\begin{array}{l}\text { Efeitos } \\
\text { fixos }\end{array}$ & $\begin{array}{l}\text { Efeitos } \\
\text { fixos }\end{array}$ & $\begin{array}{l}\text { Efeitos } \\
\text { fixos }\end{array}$ & $\begin{array}{l}\text { Efeitos } \\
\text { fixos }\end{array}$ & $\begin{array}{l}\text { Efeitos } \\
\text { fixos }\end{array}$ & $\begin{array}{l}\text { Efeitos } \\
\text { fixos }\end{array}$ \\
& & & & & & \\
Dummy-I & & & & & \\
SIZE & $-0,000$ & $-0,125^{* * *}$ & 0,006 & 0,042 & $-0,110^{*}$ & 0,007 \\
ROA & $0,011^{* *}$ & 0,005 & 0,006 & $-0,002$ & $-0,017^{* * *}$ & $-0,004$ \\
LEV & $0,001^{* * *}$ & $0,000^{* *}$ & $0,001^{* * *}$ & $0,002^{* * *}$ & $0,002^{* * *}$ & $0,001^{* * *}$ \\
Intercepto & $-0,006^{* * *}$ & $-0,006^{* * *}$ & $-0,001$ & $-0,003^{*}$ & 0,001 & 0,002 \\
N & 0,085 & $0,140^{* *}$ & $0,143^{* *}$ & $0,198^{* * *}$ & $0,398^{* * *}$ & $0,211^{* * *}$ \\
F & 4.500 & 4.435 & 4.407 & 5.247 & 5.247 & 5.251 \\
Valor-p (F) & 12,75 & 10,12 & 3,34 & 15,39 & 20,00 & 12,76 \\
Rho & 0,000 & 0,000 & 0,010 & 0,000 & 0,000 & 0,000 \\
& 0,431 & 0,429 & 0,533 & 0,282 & 0,400 & 0,326
\end{tabular}

ETR_Total, ETR_Corrente, ETR_Longo_Prazo: medidas de agressividade tributária; SIZE: logaritmo natural do ativo total de firma; ROA: lucro operacional dividido pelo ativo total; LEV: dívida de longo prazo dividido por ativo total; Ano $k$ : variável dicotômica que assume valor igual a 1 quando o ano coincide com $k$ e 0 caso contrário; N: tamanho da amostra; F: estatística para significância conjunta das variáveis do modelo; Valor-p (F): valor-p correspondente à estatística F; rho: fração da variância relacionada a diferenças entre entidades; Valor-p do conjunto de variáveis de tempo: valor-p relacionado ao teste de hipóteses cuja hipótese nula é a de que as variáveis dummies de tempo são, em conjunto, iguais a zero.

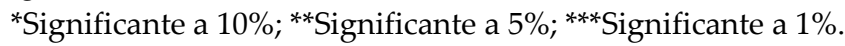

Fonte: Dados da pesquisa.

Assim, ao se observar a Tabela 6, o coeficiente de Dummy-I é estatisticamente significante apenas para ETR_Corrente e apresenta valor negativo. Com isso, somente é possível afirmar que a agressividade tributária das empresas às vésperas de serem incorporadas é inferior à dos demais casos, na média, para a proxy ETR_Corrente. A variável SIZE somente apresenta significância estatística a 10\% em 2 casos, e varia entre -0,007 e 0,015. A variável ROA somente apresenta significân- 
cia estatística a $1 \%$ em 5 casos, e varia entre 0,000 e 0,002. A variável LEV somente apresenta significância estatística a 10\% em 3 casos, e varia entre $-0,006$ e 0,001.

Foi rodada uma análise adicional, por meio da inserção de dummies para cada ano. Os resultados são qualitativamente semelhantes.

\subsubsection{Modelo 2}

O Modelo 2 visa avaliar se o nível de agressividade fiscal das empresas incorporadoras é diferente após o processo de incorporação, tendo por base a comparação com as demais companhias (modelo dif-in-dif). Os resultados são apresentados na Tabela 7, a seguir.

Tabela 7 - Resultados da regressão por efeitos fixos acrescidos de dummies temporais (modelo 2)

\begin{tabular}{lllllll}
\hline \multirow{2}{*}{ Variáveis independentes } & \multicolumn{2}{c}{ Variável dependente $($ ETR $\geq 0)$} & \multicolumn{2}{c}{ Variável dependente (sem corte) } \\
\cline { 2 - 7 } & ETR_ & ETR_ & ETR_ & ETR_ & ETR_ & ETR_ \\
& Total & Corrente & Longo_Prazo & Total & Corrente & Longo_Prazo \\
\hline Estimador & Efeitos & Efeitos & Efeitos & Efeitos & Efeitos & Efeitos \\
selecionado & fixos & fixos & fixos & fixos & fixos & fixos \\
Dummy-N $N$ & 0,002 & $-0,035$ & $-0,004$ & $-0,040$ & $-0,052^{* *}$ & $-0,028$ \\
SIZE & $0,011^{* *}$ & 0,006 & 0,006 & $-0,001$ & $-0,017^{* * *}$ & $-0,003$ \\
ROA & $0,001^{* * *}$ & $0,000^{* *}$ & $0,001^{* * *}$ & $0,002^{* * *}$ & $0,002^{* * *}$ & $0,002^{* * *}$ \\
LEV & $-0,006^{* * *}$ & $-0,006^{* * *}$ & $-0,001$ & $-0,003^{*}$ & 0,000 & 0,002 \\
Intercepto & 0,086 & $0,130^{* *}$ & $0,142^{* *}$ & $0,189^{* * *}$ & $0,386^{* * *}$ & $0,205^{* * *}$ \\
N & 4.500 & 4.435 & 4.407 & 5.247 & 5.247 & 5.251 \\
F & 12,76 & 8,59 & 3,33 & 16,17 & 21,56 & 12,91 \\
Valor-p (F) & 0,000 & 0,000 & 0,010 & 0,000 & 0,000 & 0,000 \\
Rho & 0,431 & 0,417 & 0,533 & 0,284 & 0,302 & 0,328
\end{tabular}

ETR_Total, ETR_Corrente, ETR_Longo_Prazo: medidas de agressividade tributária; SIZE: logaritmo natural do ativo total de firma; ROA: lucro operacional dividido pelo ativo total; LEV: dívida de longo prazo dividido por ativo total; Ano $k$ : variável dicotômica que assume valor igual a 1 quando o ano coincide com $k$ e 0 caso contrário; $\mathrm{N}$ : tamanho da amostra; F: estatística para significância conjunta das variáveis do modelo; Valor-p (F): valor-p correspondente à estatística F; rho: fração da variância relacionada a diferenças entre entidades; Valor-p do conjunto de variáveis de tempo: valor-p relacionado ao teste de hipóteses cuja hipótese nula é a de que as variáveis dummies de tempo são, em conjunto, iguais a zero.

*Significante a $10 \% ; *$ Significante a $5 \% ; * *$ Significante a $1 \%$.

Fonte: Dados da pesquisa.

Assim, ao se observar a Tabela 7, o coeficiente de Dummy- $N$ não é estatisticamente significante para qualquer medida de agressividade fiscal, com exceção da ETR corrente, e somente quando considerados também os prejuízos. Em análise adicional (não tabulada), os modelos foram rodados com a inserção de dummies de ano e nenhum coeficiente foi estatisticamente significante. De maneira agregada, portanto, não é possível afirmar que empresas incorporadoras sejam mais agressivas que as demais após uma operação de incorporação.

A variável SIZE somente apresenta significância estatística a 5\% em 2 casos, e varia entre 0,007 e 0,015. A variável ROA somente apresenta significância estatística a $1 \%$ em 5 casos, e varia entre 0,000 e 0,002. A variável LEV somente apresenta significância estatística a 10\% em 3 casos e varia entre $-0,006$ e 0,001 .

Estudos como os de Devos et al. (2009), que analisaram duas fontes de sinergias positivas em relação às reorganizações societárias, sejam elas operacionais ou tributárias, estimaram que a economia tributária tem uma participação tímida, contribuindo com apenas 1,64\% de um percentual de 10,03\% de ganho total. Esses resultados, em relação aos encontrados neste trabalho, possuem características diferentes no que concerne às características da amostra, pois se trabalhou somente com empresas industriais americanas. Ou seja, apenas um único segmento e em um país 
com características legislativas, políticas, econômicas e culturais diferentes da brasileira, além do lapso de tempo que também não converge com o desta pesquisa.

Mackenzie (2017) verificou se a performance econômica e as condições tributárias influenciam a atividade de M\&A na Europa. Uma das hipóteses testadas foi a de que o nível de atividade de M\&A é determinada pelo nível de tributação do país. Quanto menor a tributação, maior a atividade de M\&A. Seus resultados argumentam que essa hipótese não pode ser confirmada. Segundo a autora, a quantidade de países estudados e o período considerado pode ter sido a causa do resultado, assim, para confirmar ou rejeitar a hipótese com certeza, é necessário ampliar o número de países e o número de anos considerados. A autora chega a essa conclusão por meio de uma análise detalhada do ranking dos países, o qual deixa implícito que o percentual de tributação, particularmente o nível de Imposto de Renda, pode ser um fator contribuinte para o nível de atividade de aquisição.

Belz et al. (2013), usando a ETR, encontraram que, com a aquisição, há um aumento da agressividade tributária na adquirida em torno de 3\%, o que causa vantagem para a adquirente. Nos casos em que a empresa adquirente é mais agressiva tributariamente, há um aumento maior da agressividade na empresa adquirida depois da fusão, em torno de $8 \%$. Dessa forma, com a fusão, há uma redução na lucratividade das empresas adquiridas, porém não foi notada alteração na lucratividade das empresas adquiridas, caso elas se submetam a menor tributação que a empresa adquirente. As peculiaridades desse trabalho, em termos de comparabilidade, destacam-se em relação ao foco, ou seja, os autores analisaram a agressividade fiscal com foco na adquirida, além do destaque para negócios nacionais e internacionais. As métricas de agressividade tributária usadas pelos autores foram lucratividade e endividamento. Também foram considerados três anos depois do evento aquisição para fins de aferição da agressividade tributária.

\section{CONCLUSÃO}

Este trabalho teve por objetivo investigar duas hipóteses: $\mathrm{H}_{0}$ ) um fator para a decisão de incorporação de empresas é que estas se mostravam agressivas do ponto de vista fiscal em relação às demais companhias na véspera de sua aquisição; e $\mathrm{H}_{1}$ ) a empresa incorporadora, após a incorporação fica com maior agressividade fiscal.

Foi construída uma amostra a partir de empresas listadas na B3. O período de análise foi desde o ano de 2005 a 2017, contendo 64 companhias canceladas por incorporação e 39 empresas distintas caracterizadas como incorporadoras. As métricas utilizadas de agressividade fiscal foram três versões da ETR: corrente, total e de longo prazo. As variáveis de controle empregadas foram: o tamanho da empresa, o retorno sobre o ativo e o grau de alavancagem.

Em nenhuma das equações com métricas distintas de agressividade fiscal foi obtido coeficiente estatisticamente significante para a variável inserida com o intuito de capturar diferenças no ETR entre empresas incorporadoras e as demais empresas, desse modo, não é possível afirmar que após a reorganização societária houve aumento da agressividade fiscal no novo conglomerado empresarial. Contudo, para uma métrica de agressividade fiscal (ETR_Corrente), foi possível verificar diferenças estatisticamente significativas em tal medida entre empresas que estavam às vésperas de serem incorporadas e as demais. O ETR das primeiras é inferior, em média, ao das últimas.

Deste modo, é possível suspeitar, com base nos dados e nos modelos estimados, que a agressividade fiscal tenha influência na decisão de se incorporar uma companhia, e que também pode ser estratégia de um propenso alvo de incorporação aumentar seu nível de agressividade fiscal para que isso seja mais um atrativo ao fechamento do negócio. Importante destacar que os resultados obtidos em outras obras que versam sobre o tema são afetados, sobretudo, por realidades regionais diferentes, para mostrar que, de acordo com a influência da cultura e do sistema ju- 
rídico, econômico e político, os resultados podem mudar. Esse comparativo de resultados é de suma importância para que estudos futuros possam aprofundar mais a questão, observando outros pontos, e trazer informações mais precisas que possam influenciar decisões de investimento empresarial no que concerne às reorganizações societárias no Brasil (especificamente sobre decisões de incorporações e aquisições de empresas), e a análise, por parte do fisco, sobre essa movimentação nas empresas alvo e seus efeitos na adquirente após a reorganização societária.

Com a apresentação dos resultados desse trabalho, inicia-se o preenchimento de uma lacuna até então existente em pesquisas sobre empresas brasileiras que realizaram reorganizações societárias e seus reais efeitos tributários. Sua importância se dá pela peculiaridade da pesquisa em que pese as métricas de agressividade fiscal, as variáveis de controle, os modelos estatísticos utilizados, além do foco na análise de um clico operacional completo que contempla períodos antes e depois do negócio, e também pelo fato de a pesquisa contemplar um horizonte temporal de 12 anos que abrange períodos de crescimento e de resseção econômica.

Com efeito, tal análise não se esgota por aqui. Trabalhos futuros poderão ter foco em algumas questões, como: (a) análise detalhada das incorporações por meio de outros estudos quantitativos e qualitativos da agressividade fiscal antes das aquisições; (b) inserir outras métricas de agressividade fiscal no estudo, tais como taxa de tributação sobre valor adicionado (TTVA) e BTD, além do uso de modelos probit para a comparação de empresas mais agressivas; (c) avaliar, com mais detalhe, o efeito de uma incorporação sobre outros aspectos fiscais das incorporadoras, como, por exemplo, o caso do ágio, depreciação acelerada, entre outras despesas dedutíveis que possam ser "herdadas" após a realização de uma reorganização societária, caso sejam empresas abertas; e (d) a análise das reorganizações societárias no Brasil envolvendo multinacionais (quando as empresas brasileiras são adquiridas ou quando as empresas brasileiras adquirem), que podem influenciar decisões de investimentos internacionais.

\section{REFERÊNCIAS}

Belz, T., Robinson, L. A., Ruf, M., \& Steffens, C. (2013, 26 of December). Tax avoidance as a driver of mergers and acquisitions. SSRN - Social Science Research Network Electronic Journal, Retrieved Feb 15, 2018, from https://ssrn.com/abstract=2371706.

Blouin, J. L. (2014). Defining and measuring tax planning aggressiveness. National Tax Journal, $67(4), 875-900$.

Blouin, J. L., Collins, J. H., \& Shackelford, D. A. (2005). Does acquisition by non-US shareholders cause US firms to pay less tax? Journal of the American Taxation Association, 27(1), 25-38.

Bowman, E. H., \& Singh, H. (1993). Corporate restructuring: reconfiguring the firm. Strategic Management Journal, 14(S1), 5-14.

Callihan, D. S. (1994). Corporate effective tax rates: a synthesis of the literature. Journal of Accounting Literature, 13, 1.

Chen, S., Chen, X., Cheng, Q., \& Shevlin, T. (2010) Are family firms more tax aggressive than nonfamily firms? Journal of Financial Economics, 95(1), 41-61.

DePamphilis, D. (2017). Mergers, acquisitions, and other restructuring activities: an integrated approach to process, tools, cases, and solutions. (9a ed.). Cambridge, MA, EUA: Academic Press.

Devos, E., Kadapakkam, P.-R., \& Krishnamurthy, S. (2008). How do mergers create value? A comparison of taxes, market power, and efficiency improvements as explanations for synergies. The Review of Financial Studies, 22(3), 1179-1211. 
Dunbar, A., Higgins, D. M., Phillips, J. D., \& Plesko, G. A. (2010). What do measures of tax aggressiveness measure. Proceedings of the Annual Conference on Taxation and Minutes of the Annual Meeting of the National Tax Association, Chicago, IL, USA, 103, 18-26.

Flávio Neto, Luís. (2011). Teorias do "abuso" no planejamento tributário. Dissertação de Mestrado em Direito Tributário, Faculdade de Direito da Universidade de São Paulo, São Paulo, SP, Brasil.

Gaughan, P. A. (2011). Mergers, acquisitions, and corporate restructurings. (5th ed.). Hoboken, EUA: John Wiley \& Sons.

Hanlon, M., \& Heitzman, S. (2010). A review of tax research. Journal of Accounting and Economics, 50(2-3), 127-178.

Hayn, C. (1989). Tax attributes as determinants of shareholder gains in corporate acquisitions. Journal of Financial Economics, 23(1), 121-153.

Jensen, M. C., \& Ruback, R. S. (1983). The market for corporate control: the scientific evidence. Journal of Financial Economics, 11(1-4), 5-50.

Jordão, R. V. D., \& Oliveira, G. R. (2016). Gestão tributária nas atividades de reorganização societária em empresas de Minas Gerais. Enfoque: Reflexão Contábil, 35(3), 139-157.

Kaplan, S. (1989). Management buyouts: evidence on taxes as a source of value. The Journal of Finance, 44(3), 611-632.

Lei Complementar n. 104. (2001, 10 janeiro). Altera dispositivos da Lei $n^{0}$ 5.172, de 25 de outubro de 1966. Diário Oficial [da] República Federativa do Brasil - Eletrônico, Poder Legislativo, Brasília.

Lei n. 5.172 (1966, 25 outubro). Dispõe sobre o Sistema Tributário Nacional e institui normas gerais de direito tributário aplicáveis à União, Estados e Municípios. Diário Oficial [da] República Federativa do Brasil, Poder Legislativo, Brasília.

Lei n. 6.404 (1976, 15 dezembro). Dispõe sobre as sociedades por ações. Diário Oficial [da] República Federativa do Brasil, Poder Legislativo, Brasília.

Lei n. 10.406 (2002, 10 janeiro). Institui o Código Civil. Diário Oficial [da] República Federativa do Brasil, Poder Legislativo, Brasília.

Mackenzie, I. (2017). Mergers \& acquisitions in the European Union: acquisition activity \& economic performance. Economic Studies \& Analyses/Acta VSFS, 11(2).

Martinez, A. L. (2017). Agressividade tributária: um survey da literatura. Revista de Educação e Pesquisa em Contabilidade (REPeC), 11(spe), 106-124.

Martinez, A. L., \& Coelho, L. F. A. (2016). Planejamento tributário com operações societárias: critérios de validade utilizados pelo CARF. Revista Contemporânea de Contabilidade, 13(30), 193-213.

Martinez, A. L., Ribeiro, A. C., \& Funchal, B. (2015). The Sarbanes Oxley act and taxation: a study of the effects on the tax aggressiveness of Brazilian firms. Anais do Congresso USP de Controladoria e Contabilidade, São Paulo, 15.

Martins, E., Gelbcke, E. R., Santos, A., \& Iudícibus, S. (2013). Manual de contabilidade societária: aplicável a todas as sociedades de acordo com as normas internacionais e do CPC. (2a ed.). São Paulo: Atlas.

Omer, T. C., Molloy, K. H., \& Ziebart, D. A. (1991). Measurement of effective corporate tax rates using financial statement information. Journal of the American Taxation Association, 13(1), 57-72.

Plesko, G. A. (2003). An evaluation of alternative measures of corporate tax rates. Journal of Accounting and Economics, 35(2), 201-226.

Reale, M. (1998, 19 de outubro). Inconstitucionalidade de congelamentos. Folha de São Paulo, A-3.

Ridolfo Neto, A. (2012). Introdução às operações de fusões, aquisições e reestruturação societária: métodos mais utilizados para a precificação de empresas. In: Rocha, D. S. R., \& Teixeira, E. D. 
(Coords.). Direito societário: fusões, aquisições, reorganizações societárias e due diligence. São Paulo: Saraiva, 21-34.

Santos, R. B. (2014). O planejamento tributário em reorganizações societárias. São Paulo: Quarter Latin.

Scholes, M. A., \& Wolfson, M. M. (1992). Taxes and business strategy: a planning approach. Engelwood Cliffs, NJ: Prentice-Hall.

Schoueri, L. E. (2015). Brazil. In: Brauner, Y., \& Pistone, P. BRICS and the emergence of international tax coordination. Amsterdam: IBFD, 41-77.

Shackelford, D. A., \& Shevlin, T. (2001. Empirical tax research in accounting. Journal of Accounting and Economics, 31(1-3), 321-387.

Terres Junior, J. C., Borba, J. A., \& Souza, M. M. (2011). Reorganizações societárias: uma análise dos processos de cisão arquivados na JUCESC entre os anos de 2006 e 2008. Revista Universo Contábil, 7(1), 36-48. 